Cómo citar este artículo en MLA: Cortés Castillo, Darío E. y Paola Alexandra Sierra-Zamora.

"Buen vivir, vivir bien y el choque de paradigmas". Escritos 27. 59 (2019): 319-343. doi: http://dx.doi.org/10.18566/escr.v27n59.a07

Fecha de recepción: 23.01.2019

Fecha de aceptación: 08.05.2019

\title{
Buen vivir, vivir bien y el choque de paradigmas ${ }^{1}$
}

Good Life, Living Well, and the Clash of Paradigms

Bom viver, viver bem e o choque de paradigmas

\author{
Darío E Cortés Castillo ${ }^{2}$ \\ Paola Alexandra Sierra-Zamora ${ }^{3}$
}

1 Artículo de investigación que expone resultados de investigación del proyecto titulado: "Estrategia nacional. Por una Política de Seguridad y Defensa a la vanguardia de las amenazas contemporáneas" del Grupo de Investigación "Masa Crítica" reconocido y categorizado como C por Colciencias y registrado con el código COL0123247, adscrito a la Escuela Superior de Guerra "General Rafael Reyes Prieto" y financiado por el Departamento Administrativo de Ciencia, Tecnología e Innovación COLCIENCIAS.

2 Profesor investigador Departamento de Estrategia Escuela Superior de Guerra (Colombia). Magíster en inteligencia estratégica y prospectiva Universidad Jaume I (España). Magíster en inteligencia estratégica Escuela de inteligencia Bg. Ricardo Charry Solano. Contacto: cortesd@esdegue.edu.co.

3 Abogada de la Universidad Católica de Colombia. Magíster en Derechos Humanos, Democracia y Justicia Internacional por la Universitat de Valéncia (España). Doctorado (en curso) del programa de Derechos Humanos, Democracia y Justicia Internacional por la misma casa de estudios (2016-2019). Gestor de Investigación del Centro de Estrategia de la Escuela Superior de Guerra. Contacto: paola.sierra@esdegue.edu.co. 


\title{
RESUMEN
}

Culminada la Guerra Fría, la sociedad global consideró superadas la colisión ideológica y la polarización de teorías. Sin embargo, al finalizar el siglo xx y descollando el siglo XXI surgieron indicios que apuntaban en dirección contraria. Los primeros con el resurgimiento del marxismo que a partir de la tesis humanista de la filosofía de la praxis revive desde Latinoamérica el legado de Mariátegui, el Che Guevara y Camilo Torres R. El artículo se pregunta si el paradigma del marxismo humanista arroga los fundamentos del buen vivir o vivir bien para enfrentar al capitalismo neoliberal y su proyecto desarrollista. La aproximación al tema se hace de manera cualitativa y descriptiva. A través del método de análisis del discurso político expuesto en la teoría crítica al desarrollismo (Escobar 191) se aborda la caracterización del capitalismo neoliberal y el modelo de desarrollo, continuando con las tesis que desde el marxismo humanista y la estrategia de revolución cultural se estructura para la emancipación en Latinoamérica. Finalmente, se exponen los planteamientos del buen vivir a partir de la apropiación que hacen los neomarxistas para dar la batalla contra el capitalismo neoliberal.

Palabras clave: Resistencia; Buen vivir; Vivir bien; Hegemonía; Paradigma.

\begin{abstract}
At the end of the Cold War, global society thought that the clash of ideologies and the polarization of theories had been overcome. However, at the end of the twentieth century and the beginning of the twenty-first, there were clear signs that that was not the case. The first of those signs was the comeback of Marxism, which based on the humanist idea of the philosophy of praxis brings back the legacy of Jose Carlos Mariategui, Ernesto "Che" Guevara and Camilo Torres in Latin America. The article considers whether the paradigm of Marxist Humanism appropriates the principles of good life or living well to face Neoliberalism and its development project. The approach to the issue is qualitative and descriptive. Through the analysis of political discourse suggested in development criticism (Escobar 191), the article addresses the characterization of Neoliberalism and the development model. It also addresses the thesis advanced by Marxist Humanism and the strategy of cultural revolution for emancipation in Latin America. Finally, it presents how Neo-Marxists appropriate and understand good life to face Neoliberalism.
\end{abstract}

Key words: Resistance; Good Life; Living Well; Hegemony; Paradigm.

\section{RESUMO}

Depois da Guerra Fria, a sociedade global considerou superada tanto a colisão ideológica quanto a polarização das teorias. Contudo, ao finalizar o século XX e começar o século XXI surgiram sinais que assinalavam para a direção contrária. As primeiras com o reaparecimento do marxismo que a partir da tese humanista da filosofia da práxis revive desde América Latina a herança de Mariátegui, o Che Guevara e Camilo Torres R. Esse artigo se pergunta se o paradigma do marxismo humanista possibilita os fundamentos do bom viver ou viver bem para confrontar 
o capitalismo neoliberal e seu projeto de desenvolvimento. A abordagem é de tipo qualitativo e descritivo. A partir do método de analise do discurso politico exposto na teoria critica ao desenvolvimento (Escobar 191) se trata a caracterização do capitalismo neoliberal e o modelo de desenvolvimento, depois tratam-se a tese do marxismo humanista e da estratégia de revolução cultural que se estruturaram para a emancipação da América Latina. Finalmente, expõem-se as propostas do bom viver a partir da apropriação que fazem os neo-marxistas para lutar contra o capitalismo neoliberal.

Palavras chaves: Resistência; Bom viver; Viver bem; Hegemonia; Paradigma.

\section{Introducción}

$\mathrm{P}$ ara una adecuada comprensión de los fenómenos sociales que se registran en América Latina se hace necesario lanzar una mirada exploratoria al contexto de confrontación, en el marco de la crisis del capitalismo neoliberal, dentro del sistema civilizatorio de la modernidad (Coraggio 167) y el resurgimiento del marxismo. Esta mirada evidencia un nuevo choque de paradigmas, entendidos, en el sentido sociológico, como las verdades, valores y creencias que una comunidad ha estructurado en su devenir para la resolución de un enigma o problema. Como lo recuerda Amparo Gómez al citar a Kuhn, el paradigma se relaciona con la constelación de creencias, valores, técnicas compartidos por los miembros de una comunidad dada (...) con ejemplares, elementos en tal constelación, que empleados como modelos o ejemplares, guían la investigación de soluciones a enigmas concretos, que pueden reemplazar a las reglas explícitas como base para la solución de los restantes enigmas de la ciencia normal (143)

Ante el triunfo del capitalismo sobre el comunismo soviético e instauradas las tesis del capitalismo neoliberal como modelo hegemónico global, sectores de intelectuales de América Latina reeditaron un nuevo modelo de revolución marxista que toma al ser humano como sujeto colectivo de la revolución. Para esto, se inspiraron en las tesis del marxismo humanista y recogieron el legado de Antonio Gramsci. Pero, además, involucraron la cosmovisión y las luchas de resistencia de los pueblos ancestrales, con el fin de articular la resistencia latinoamericana hacia su emancipación mediante la destrucción del paradigma hegemónico. 
(...) "implica deconstruir el edificio economicista capitalista", lo que a su vez involucra tanto la confrontación de intereses hegemónicos como la construcción de nuevos sujetos y visiones del desarrollo y del mundo, de todo un nuevo entramado de discursos y de prácticas con respecto a lo humano y lo natural y, en última instancia, la vida misma. (Escobar 191)

De esta manera, el choque de teorías expone y pone en tela de juicio, desde la vertiente humanista del marxismo, las verdades, los valores y el modelo de sociedad que hasta ahora se ha estructurado e impuesto a partir de la perspectiva del capitalismo neoliberal. Este último es calificado como un "sistema explotador en crisis responsable del subdesarrollo, la desigualdad, la destrucción de la madre tierra, la enajenación y la permanente pérdida de la soberanía de los pueblos" (Grupo de Trabajo Foro de Sao Pablo 4), que exige la emergencia de nuevos modelos inspirados en la historicidad de los pueblos latinoamericanos que conduzcan a la región hacia la segunda y definitiva independencia. Como lo plantea Girbal:

América Latina vive desde hace unas décadas tensionada por paradigmas en jaque, crisis de modelos y de teorías, ausencia de proyectos políticos de largo plazo, que alimentan el desconcierto en sus sociedades. Todo parece indicar, diría Hannah Arendt, que estamos en "un extraño periodo intermedio determinado por cosas que ya no son y por cosas que aún no han sido y que, en la Historia, esos intervalos, más de una vez mostraron poder contener el momento de la verdad. Desde estas perspectivas, resulta un desafío interesante pensar el tránsito hacia la segunda independencia continental para encarar la superación, rescatando continuidades con la historia fundacional de las naciones. (Girbal 67)

En esa medida, corresponde abordar de manera sistémica la interrelación teórica entre la caracterización del capitalismo neoliberal a la luz de la teoría crítica al desarrollismo, las tesis de la filosofía de la praxis y la revolución cultural, y los saberes del buen vivir o vivir bien expuestos por los pueblos ancestrales y arrogados por el paradigma humanista del marxismo latinoamericano como tesis emancipadora. En ese sentido, "una teoría social es crítica en la medida en que busca la emancipación humana” (Munck 36). 


\section{Discusión}

\section{La crisis del paradigma capitalista}

En el escenario de confrontación de paradigmas, surgen, en Latinoamérica, tesis renovadoras provenientes del neomarxismo o marxismo humanista que, al rescatar los postulados de alienación, enajenación y cosificación del hombre expuestos por el joven Marx en los manuscritos económicos filosóficos de 1844, toman distancia de las tesis de la ortodoxia del socialismo real y amalgaman diversas corrientes de pensamiento crítico para construir un discurso de contenido humanista. Así, superando los errores el socialismo real, exponen "más allá de todos los cambios económicos, una revolución de la historia de la esencia humana" (Marcuse 19).

El neomarxismo, independientemente de las diversas corrientes que se incluyen dentro de él, se considera por lo común aquel que se distanció del "marxismo oficial" establecido en los países del llamado "socialismo real". Sus antecedentes se encuentran entre otros en el intento de utilizar el marxismo para analizar autocríticamente el propio marxismo y renovarlo (Korsch), destacarlo como "filosofía de la praxis" (Gramsci) y se identifica mayormente con la teoría crítica de la Escuela de Frankfort (Horkheimmer, Adorno, Habermas) sobre la cultura, la comunicación (...) y algunas transformaciones operadas en el capitalismo contemporáneo. (Biagini \& Roig 370)

El capitalismo neoliberal promueve la idea individualista de la libertad como el principio fundamental de la ordenación natural de la economía hacia el logro del bien común, del vivir mejor y de la calidad de vida de acuerdo con las circunstancias en las que solo el trabajo de hombres libres e interesados acarrea bienestar (Sada, D. 66). Esta última se ha convertido en la "ideología política y económica dominante" (De Sousa 163); por esa razón, en la actual fase de deconstrucción del modelo desarrollista, dichas premisas alientan innumerables críticas que, provenientes del pensamiento neomarxista latinoamericano, apuntan a señalar profundas contradicciones con sus postulados. Esto se expresa, por ejemplo, en que:

El "vivir mejor" supone una ética de progreso ilimitado y nos incita a una competición con los otros para crear más y más condiciones para "vivir 
mejor". Sin embargo, para que algunos puedan "vivir mejor", millones de personas han tenido que vivir mal. Es la contradicción capitalista. (Boff 2)

De igual manera, en su práctica, el capitalismo neoliberal como modelo global hegemónico (De Sousa 148) expone una situación que ha promovido el consumismo incontrolado y el crecimiento ilimitado, conduciendo a la explotación indiscriminada y a la degradación de los recursos naturales sin dar tregua a la recuperación del planeta. En su lógica, los fenómenos actuales de la humanidad, tales como inequidad, pobreza y contaminación ambiental, son evidencia de profundas contradicciones a sus postulados.

El problema de la pobreza, de la contaminación ambiental, las crisis sociales recurrentes y la globalización excluyente demandan día a día de la reorientación de los modelos de desarrollo hacia opciones más cercanas a nuestros postulados ancestrales y la conservación de nuestros recursos y fuentes de agua; para tal fin debemos (...) abordar el desarrollo económico teniendo en cuenta nuevas propuestas y paradigmas. (Cabrales 90)

Desde dicha interpretación, el choque de teorías en la región pone en tela de juicio las verdades, los valores y el modelo de sociedad que hasta ahora se han estructurado e impuesto desde la perspectiva del capitalismo neoliberal. Así, "el sistema capitalista y su historia de conquista, colonialismo y neocolonialismo son la causa del subdesarrollo que caracteriza a nuestras economías, a nuestras sociedades y a la conciencia social de los individuos" (Grupo de Trabajo Foro de Sao Pablo 9), por lo que se requiere la creación de una nueva conciencia social mayoritaria que inspire las luchas por la emancipación latinoamericana.

El neoliberalismo es, ante todo, una cultura del miedo, del sufrimiento y la muerte para las grandes mayorías; no es posible combatirlo con eficacia sin oponerle una cultura de la esperanza, la felicidad y la vida. (...) Una vez ampliada la realidad sobre la que hay que actuar políticamente, las propuestas de las izquierdas deben resultar creíbles para las grandes mayorías como prueba de que es posible luchar contra la supuesta fatalidad del miedo, del sufrimiento y la muerte en nombre del derecho a la esperanza, la felicidad y la vida. Esta lucha debe orientarse por tres principios clave: democratizar, desmercantilizar y descolonizar. (De Sousa 147) 
Con respecto a esta interpretación, el modelo marxista humanista pretende enfrentar la propuesta hegemónica del capitalismo caracterizada por el establecimiento de una forma universal de ver y pensar las realidades que conducen a que una sociedad alienada se someta a los preceptos del pensamiento único como exclusivo modo de vida (Lukács 20). De esta manera, se expone la revolución cultural como eje central de la transformación. En una entrevista realizada por Eneko Calle y Javier González, Ana Esther Ceceña refiere que:

Hablar de hegemonía capitalista equivale a reconocer el hecho de que la gente piensa que el capitalismo es el único modo de vida posible, el modo de vivir de que alguna manera puede acomodar o no, pero que no tiene remedio. La hegemonía hace posible que se asuma como propia esta manera de entender el mundo. Eso es lo que yo entiendo por hegemonía, a partir de los planteamientos de Gramsci. (Ceceña, A. 1)

En perspectiva, el capitalismo neoliberal con su teoría del desarrollo es profundamente cuestionado. Esto se da por su apego al crecimiento económico que, en el ejercicio de sus prácticas, refuerza la dinámica de explotación y dependencia de los países sometidos a las relaciones de dominio de los países desarrollados, haciendo de la emancipación una necesidad. Según Dos Santos, citado por Sotelo:

La dependencia es una situación donde la economía de cierto grupo de países está condicionada por el desarrollo y expansión de otra economía, a la cual se somete aquella (...) La situación básica de dependencia lleva a los países dependientes a una situación global que los mantienen atrasados y bajo la explotación de los países dominantes. (Sotelo 187)

En este sentido, el modo de producción capitalista que fundamenta el progreso de los seres humanos en el desarrollo económico "mediante el acceso de la sociedad a un conjunto de bienes y servicios" (Gudynas 173) dista mucho de ser una realidad. En este ejercicio mecanicista, se constatan la inequidad, el consumismo, el egoísmo, el individualismo, la precarización, la exclusión y la sobreexplotación del trabajo. De acuerdo con Bertinat:

Se anuda el desarrollo a la producción de bienes, que, en los hechos no están distribuidos equitativamente y que además experimentan en la mayoría de 
los casos un fuerte proceso de reducción de su vida útil, ya sea por cuestiones meramente técnicas como culturales, lo que los transforma en algún tipo de residuo. Esto demuestra que la lógica de este proceso es esencialmente perniciosa para la mayoría de la población y, a mediano y largo plazo destructiva, para la humanidad en su conjunto. (5)

De esta manera, los analistas de las dinámicas sociales, fundamentados en las teorías del sistema mundial, de la dependencia y del modelo de transformación emancipatoria, coinciden en calificar al modelo de desarrollo imperante como ineficiente, caduco y contradictorio al logro de la felicidad. Según ellos, este modelo produce una crisis estructural y civilizatoria del modo de producción capitalista (Sotelo 178). En su práctica, el capitalismo refleja destrucción social y de la naturaleza llevándolo, ante la pérdida del consenso, a la mera coerción:

Es un capitalismo que avanza destruyendo. Esto se ve claramente en la naturaleza, pero también en lo social, ya que cada vez es más excluyente y menos capaz de garantizar la reproducción de la sociedad en la que actúa; esto lo lleva a fortalecer su lado disciplinario y militarista para enfrentar el creciente rechazo de la ciudadanía. (Ceceña 2)

Según lo expuesto, desde los nuevos sujetos colectivos que se articulan en la diversidad, se engendran nuevas formas concomitantes de ver la vida (Escobar 202). Fundamentados en múltiples visiones del mundo y del desarrollo, estos sujetos construyen proyectos alternativos que apuntan a la transición del modelo desarrollista deshumanizado a partir de un proyecto que en la praxis defienda la "dignidad humana, la naturaleza y otra democracia" (Coraggio 168). En síntesis, Según Coraggio, para Escobar y Segato "lo que está bajo crítica no son solamente las políticas de los gobiernos neoliberales, o la relación de dependencia de la periferia, o el sistema capitalista, sino el sistema civilizatorio de la modernidad eurocéntrica, que en el siglo xx se constituyó como proyecto desarrollista" (167).

De ahí que su propuesta contemple la valorización de las expresiones de resistencia social y "la revalorización de las culturas vernáculas", como insumos que permitan subvertir el conocimiento impuesto por la cosmovisión totalizadora del modelo desarrollista del capitalismo neoliberal (Katz 218). 


\section{América Latina y su autenticidad teórica desde la revolución cultural del marxismo humanista}

En la década de los años noventa, después de verificar las críticas al modelo capitalista, se estructuro, en el Foro de Sao Pablo y con el liderazgo cubano, una novedosa forma de articular las tesis revolucionarias para enfrentar el paradigma capitalista neoliberal en América Latina.

Con este propósito, los intelectuales neomarxistas latinoamericanos, haciendo una autocrítica del marxismo ortodoxo y con el fin de enfrentar al capitalismo y superar los errores del socialismo real, acuden a las tesis humanistas del Marx joven de los manuscritos económicos-filosóficos o de París de 1844 (Cortés \& Cerón 57). En estos documentos, el filósofo de Tréveris criticó la economía política, la división del trabajo y el capital de Adam Smith y planteó el problema de la alienación y la enajenación, fundamento de la necesaria liberación y emancipación del hombre:

Cuanto menos eres, cuanto menos exteriorizas tu vida, tanto más tienes, tanto mayor es tu vida enajenada y tanto más almacenas de tu esencia (...) Todo lo que el economista te quita en vida y en humanidad te lo restituyen en dinero y riqueza, y todo lo que no puedes lo puede tu dinero (...). La enajenación aparece tanto en el hecho de que mi medio de vida es de otro; que mi deseo es la posesión inaccesible de otro; como en el hecho de que cada cosa es otra que ella misma, que mi actividad es otra cosa, que, por último, domina en general el poder inhumano. (Marx 160)

En este orden de ideas, desde el marxismo humanista, los revolucionarios latinoamericanos, evocando los legados de Ernesto el Che Guevara, José Carlos Mariátegui y Camilo Torres Restrepo, recogen las tesis de la filosofía de la praxis y la estrategia de revolución cultural de Antonio Gramsci y estructuran un modelo revolucionario en el que la batalla por las verdades y los valores desde el movimiento social y popular fundamenten la lucha por la hegemonía:

Desde el movimiento social popular alternativo, lo político supone la necesidad de concebir y construir valores alternativos a los del capital, contra hegemónicos, que devengan, a su vez, germen de un nuevo modelo de estatalidad y de poder popular cuyo horizonte sea la emancipación socialhumana como proceso histórico. (Galfisa 3) 
La manera como ha de producirse la transformación de las ideas y de la realidad se concibió desde la mutación del sentido común o, como lo llama Sousa Santos, nuevo sentido común contrahegemónico (Lao 159). Estas ideas buscan que el individuo corriente se desprenda de la conciencia ordinaria de la cotidianidad impuesta por la visión capitalista y adopte una conciencia reflexiva que conduzca, desde la praxis revolucionaria, a la transformación creadora de la realidad (Sánchez 23).

En esta intención se elabora una nueva concepción de la subversión, una que construye un nuevo discurso y unas nuevas metodologías desde las que se concibe al pensamiento como instrumento de la hegemonía popular y promotor de las cosmovisiones ancestrales. Estas mutaciones se orientan hacia la transformación emancipadora de la humanidad y la superación del modelo de "sociedad patriarcal, de desarrollo extractivista y depredador, de sumisión neocolonial, de pensamiento único, de patrones culturales únicos y del modelo de gobierno impuesto por el capitalismo" (Lang \& Brand 8). De ahí que desde el Foro de Sao Pablo se plantee:

Nos proponemos con este programa superar un sistema explotador en crisis, responsable del subdesarrollo, la desigualdad, la destrucción de la Madre Tierra, la enajenación y la permanente perdida de la soberanía de nuestros pueblos. (Grupo de Trabajo Foro de Sao Pablo 4)

Otra de las expresiones revolucionarias contra el modelo capitalista globalizador surge en México el primero de enero de 1994, con el alzamiento insurreccional zapatista. Este movimiento fue incubado en la comunidad indígena y tomó distancia de los errores del socialismo real. Se autodenominó Ejército Zapatista de Liberación Nacional -EZLN- y, bajo las consignas, "basta ya" y "otro mundo es posible", se enfrentó a las condiciones neocoloniales de explotación y dominación global (Cortés 62). Como lo manifiesta Ceceña:

Efectivamente, la insubordinación zapatista, ni más ni menos que contra el neoliberalismo, puso de relieve la universalidad de los sistemas de explotación y dominación, pero también la universalidad de la proletarización y la resistencia. La diversificación y complejización de los procesos de trabajo, así como de las formas de explotación que pone en marcha un sistema de alcance planetario, combina necesariamente historias, experiencias, culturas, 
condiciones geográficas y climáticas con requerimientos concretos de la producción y con capacidades tecnológicas que amplían constantemente la gama de saberes susceptibles de apropiación. (304)

El legado del proceso zapatista destaca la lucha de resistencia histórica de los pueblos ancestrales contra la práctica expoliadora del poder extranjero, la actitud traidora de las élites domésticas y la voracidad del dinero. Ante las circunstancias de explotación, dominación, discriminación, exclusión y humillación, el EZLN promueve una nueva forma de hacer la revolución, en la que, superando la estrecha visión economicista, reasigna el sujeto de la revolución en la diversidad del sujeto colectivo. Desde esta postura, el movimiento promueve su sentido de realidad, su historia y su voluntad, que por su tenacidad marca el derrotero de la confrontación civilizatoria.

Desde este contexto de transformación del quehacer revolucionario, la revolución cultural (Streck, Redín y Zitkoski 26) emerge como modelo a seguir. En este, la transformación del sentido común pasa por una acción en doble dirección de deconstrucción - construcción. Por una vía se desalienan las verdades y valores construidos por el modelo capitalista, mientras que, por la otra, se aliena con la propuesta emancipadora. En esta dinámica, tomando como objetivo la conquista de la hegemonía y de manera silenciosa, sutil y altamente destructiva, se contempla un combate intelectual y moral en el seno de la sociedad civil que produzca la absorción de la sociedad política y la supresión del modelo imperante. Desde esta reflexión, el modelo examina y afirma:

¿Cómo hacerse con la sociedad civil, esa amalgama de ideas, creencias, aptitudes, aspiraciones? La respuesta de Gramsci pasa por una comprobación: la sociedad civil está «poblada» de elementos culturales: modos de pensar, de sentir, de situarse ante la vida, de leer, de divertirse (...). Se trata, por tanto, de conquistar la cultura para el marxismo, de organizar la cultura por medio de la captación de sus agentes, los intelectuales. (Del Noce 17)

Así, tras identificar la cultura como el botín por asaltar, la transformación de la cosmovisión fundada en la visión trascendentalista del mundo debe ser removida por una cosmovisión intramundana y secularista. Para el caso de América Latina, en la formulación de la confrontación cultural hacia la conquista del poder desde abajo y desde los movimientos sociales, se acudió 
a la teología de la liberación y al rescate de la cosmovisión de los pueblos ancestrales como fórmula de articulación de la diversidad del pueblo latino en la enunciación de un nuevo paradigma. En esa medida:

Desde el movimiento social popular alternativo, lo político supone la necesidad de concebir y construir valores alternativos a los del capital, contrahegemónicos, que devengan, a su vez, germen de un nuevo modelo de estatalidad y de poder popular cuyo horizonte sea la emancipación social-humana como proceso histórico: Socialismo, Buen Vivir, complementariedad, apropiación colectiva, unidad, solidaridad, dignidad humana, participación, distribución, perspectiva de género y diversidad sexual, medioambiente y sustentabilidad ecológica, biodiversidad, soberanía alimentaria, plurinacionalidad, multiculturalidad, colectividad, igualdad, equidad, justeza, antimilitarismo y paz, autoestima popular, pensamiento crítico y creador, saber ecologizado e integrador. (Galfisa 3)

\section{El paradigma del buen vivir como alternativa al modelo de desarrollo capitalista: buen vivir y socialismo del siglo XXI}

Después de más de cinco siglos de dominación capitalista, en Latinoamérica se toma la experiencia de la resistencia de los pueblos ancestrales como ejemplo a seguir en la configuración de un nuevo marxismo. Así, apropiándose de sus legados, sus costumbres y tradiciones, se estructura el proceso civilizatorio anti sistémico ${ }^{4}$, que inspire y aliente al sujeto colectivo en su intención emancipadora, una intención que tiene que ver con "los procesos tendientes a la liquidación de las propias relaciones de sujeción y poder” (Valdés. 8). Por esa razón:

Cinco siglos de colonización y subordinación al capitalismo mundial en América Latina y el Caribe han producido un complejo de dominación que estamos obligados a conocer muy bien, para poder destruirlo y superarlo, y que no pueda renacer y reproducirse bajo nuevas formas (...) Tenemos que recuperar la historia de las revoluciones y de las luchas rebeldes, la historia de

4 Santiago Armesilla Conde. El antisistema será aquel que se oponga de manera frontal a una Totalidad Sistemática. Circular dada sea esta el Estado o el Sistema de Modos de Producción. Revista crítica El Catoblepas. No 68. 2007. ISSN: 1579-3974. 
las resistencias múltiples y diferentes a las diferentes formas de dominación sociales y humanas que han formado un todo finalmente con la dominación del capitalismo, y que encuentran su último sentido y su capacidad de mandar o de sobrevivir en esa dominación capitalista. (Martínez 4)

En esta construcción civilizatoria antisistémica emerge, sin reñir con los diversos sujetos sociales desde la cosmovisión indígena, la concepción del sumak qamaña (Vivir bien) y sumak kawsay (Buen vivir). La primera tiene que ver con la relación armónica entre el hombre y la naturaleza; en esa medida, reconoce la madre tierra (pachamama) como algo sublime que en su respeto y cuidado permite vivir en plenitud. La segunda acepción se aproxima a la misma concepción de vida en plenitud, teniendo tan solo la diferenciación lingüística entre el aymara y el quechua respectivamente.

\begin{abstract}
El Buen Vivir nos plantea un nuevo horizonte de vida que debemos resignificar para el socialismo. La cosmovisión indígena rescata el tema de la vuelta a la tierra enfrentando el despojo etnocida de las empresas transnacionales en complicidad con los estados neoliberales. El sumak kawsay reta a entablar otras relaciones con la naturaleza y entre los seres humanos, a recuperar el diálogo que los pueblos tradicionales han tenido con la tierra, pero también nos desafía a entender las identidades culturales de los diversos sujetos sociales que integran estos países. (Galfisa 1)
\end{abstract}

Según lo expuesto desde el movimiento neomarxista que toma la sabiduría de los pueblos ancestrales, se hace necesario un cambio estructural que elimine el modelo liberal de Estado Nación. La principal justificación es que con este modelo se fundamentó el proceso de desestructuración cultural, el despojo de las tierras, la superposición cultural y el proceso de homogenización con el que, tras excluir, explotar y discriminar a los pueblos originarios, se benefició a las elites apoltronadas (CAOI 18).

Desde la cosmovisión ancestral, entendida como "la forma de ver, sentir percibir y proyectar el mundo" (24), se propone dar la batalla contra el modelo de desarrollo impuesto por el modelo neoliberal en el que el extractivismo, la transculturización, el neocolonialismo y el etnocidio amenazan la existencia del ser humano y de la naturaleza: 
La cosmovisión indígena rescata el tema de la vuelta a la tierra enfrentando el despojo etnocida de las empresas transnacionales en complicidad con los estados neoliberales. El sumak kawsay reta a entablar otras relaciones con la naturaleza y entre los seres humanos, a recuperar el diálogo que los pueblos tradicionales han tenido con la tierra, pero también nos desafía a entender las identidades culturales de los diversos sujetos sociales que integran estos países. (Galfisa 1)

Fundamentado en los saberes heredados de generación en generación que estructuran los principios de acuerdo con las leyes de la naturaleza, desde lo ético, el respeto a todos los seres humanos y, en especial, a la pachamama como sujeto de derecho, el paradigma humanista del marxismo organiza el modelo de sociedad comunitaria, economía distributiva, autonomías e identidad propia, donde las decisiones en beneficio o perjuicio de todos se adoptan de manera colectiva. Como lo propone Palacín:

Los pueblos indígenas tenemos principios construidos de acuerdo con las leyes de la naturaleza, somos pueblos que vivimos en comunidad, donde se practica la reciprocidad, la dualidad, la complementariedad. Nosotros tenemos conocimiento y sabiduría (...) nuestros conocimientos están acumulados en el propio pueblo y ahí los ejercemos. Por eso los derechos territoriales, los conocimientos y la justicia son ejercidos de manera colectiva, en conjunto: todos crecemos o decrecemos juntos. (9)

De esta manera, se formula la alternativa contrahegemónica que, desde la ética, considerada como el conjunto de principios y normas que tienen como fin la regulación de la conducta (Cruz, E. 12), plantea un proceso de cambio de los preceptos del capitalismo neoliberal. Así, adoptando los saberes de los pueblos indígenas se expande este proceso de cambio a nivel mundial, con el propósito de promover, de manera innovadora pero antiquísima, el modelo comunitario de la cultura de la vida en el que existe una interdependencia entre todo y todos (CAOI 11):

Todos y todo somos parte de la Madre Tierra y de la vida, de la realidad, todos dependemos de todos, todos nos complementamos. Cada piedra, cada animal, cada flor, cada estrella, cada árbol y su fruto, cada ser humano, somos 
un solo cuerpo, estamos unidos a todas las otras partes o expresiones de la realidad. (CAOI 35)

En la intención recivilizatoria, el paradigma cultural proyecta construir sus nuevos valores y realidades desde el sistema de organización de vida o ayllu (comunidad), la cual es comprendida como la unidad y estructura de vida en la que todo vive y todo es importante y en donde todas las formas de relación deben desarrollarse de manera complementaria. Con esto se buscan el equilibrio y la armonía de la vida, en los que el ser humano no puede erigirse como único referente de vida (35).

Para la promoción y consolidación del modelo organizativo de la comunidad (ayllu), la propuesta considera necesario el fortalecimiento de la conciencia del ayni o perfecto equilibrio como factores determinantes del vivir bien. Desde esta conciencia, se estructuran las relaciones políticas, económicas, educativas, jurídicas y agrícolas que direccionan el comportamiento.

Con el propósito de lograr una aproximación a la manera en que se confronta el modelo de desarrollo capitalista neoliberal desde los saberes del buen vivir o vivir bien y sin pretender tomar el todo, el siguiente cuadro (de elaboración propia) recoge diversas opiniones para exponer las diferencias conceptuales en el abordaje de algunos factores comunes. Para la elaboración de la tabla se acudió a los aportes de la Coordinadora Andina de Organizaciones Indígenas, Ana Ester Ceceña, Omar Cabrales, Javier Medina, María Luisa Durán López y Katu Arconada.

\begin{tabular}{|c|c|c|c|}
\hline $\begin{array}{c}\text { Factor/ } \\
\text { Paradigma }\end{array}$ & Capitalismo & Buen vivir & $\begin{array}{l}\text { Fundamento } \\
\text { del buen vivir }\end{array}$ \\
\hline Cosmovisión & $\begin{array}{l}\text { Monoteísta, } \\
\text { monoculturalista, } \\
\text { eurocentrista } \\
\text { (Cabrales, O. 88) }\end{array}$ & $\begin{array}{l}\text { El ser humano y la } \\
\text { Pachamama forman un } \\
\text { conjunto vivo, un todo en } \\
\text { una relación estrecha y } \\
\text { perpetua. } \\
\text { Nada está separado, } \\
\text { todo está unido y todos } \\
\text { evolucionamos. La } \\
\text { naturaleza es sujeto no } \\
\text { objeto. }\end{array}$ & Principio Ético Moral. \\
\hline
\end{tabular}




\begin{tabular}{|c|c|c|c|}
\hline $\begin{array}{c}\text { Factor/ } \\
\text { Paradigma }\end{array}$ & Capitalismo & Buen vivir & $\begin{array}{l}\text { Fundamento } \\
\text { del buen vivir }\end{array}$ \\
\hline Civilización & $\begin{array}{l}\text { Unidimensional, } \\
\text { no relacional. } \\
\text { Existencia } \\
\text { separada y } \\
\text { monádica, } \\
\text { excluyente. }\end{array}$ & $\begin{array}{l}\text { Lo contradictorio, } \\
\text { incluyente }\end{array}$ & $\begin{array}{l}\text { Complementariedad } \\
\text { de opuestos (Medina } \\
\text { 41), tercero incluido } \\
\text { (Medina 42). } \\
\text { Principio } \\
\text { contradictorio } \\
\end{array}$ \\
\hline Tipo de Cultura & $\begin{array}{l}\text { Antropocéntrica, } \\
\text { monosujéticas, } \\
\text { carácter jerárquico } \\
\text { y utilitario. }\end{array}$ & $\begin{array}{l}\text { Plurisujéticas, interacción y } \\
\text { complementariedad. }\end{array}$ & $\begin{array}{l}\text { Interculturalidad } \\
\text { (Medina 40). }\end{array}$ \\
\hline Modelo de Estado & Estado Nación. & $\begin{array}{l}\text { Plurinacional, autonomías, } \\
\text { autogobierno, democracias } \\
\text { comunitarias. }\end{array}$ & $\begin{array}{l}\text { Proceso estatuyente } \\
\text { (Exeni 146), libre } \\
\text { determinación. }\end{array}$ \\
\hline Ejercicio Político & $\begin{array}{l}\text { Representativa, } \\
\text { jerárquica }\end{array}$ & $\begin{array}{l}\text { Participativo, desde abajo, } \\
\text { no lineal y en constante } \\
\text { movilidad. Que satisfagan } \\
\text { las necesidades materiales, } \\
\text { sí, pero también la } \\
\text { consecución de una calidad } \\
\text { de vida (y muerte) digna, la } \\
\text { armonía con la naturaleza, } \\
\text { el potenciar de nuestras } \\
\text { culturas, el tiempo libre, } \\
\text { la reconstrucción de lo } \\
\text { público. }\end{array}$ & $\begin{array}{l}\text { Transversal a la } \\
\text { armonía con la } \\
\text { Madre Tierra, la } \\
\text { descolonización y la } \\
\text { despatriarcalización. }\end{array}$ \\
\hline Economía & $\begin{array}{l}\text { Acumulación de } \\
\text { riqueza de capital, } \\
\text { individualista } \\
\text { utilitarismo. }\end{array}$ & $\begin{array}{l}\text { Economía complementaria } \\
\text { y de reciprocidad con la } \\
\text { vida, la Madre Tierra, la } \\
\text { comunidad y la familia. } \\
\text { La forma en que seres } \\
\text { humanos y comunidades } \\
\text { deciden relacionarse } \\
\text { con todas las formas de } \\
\text { existencia. }\end{array}$ & $\begin{array}{l}\text { Leyes naturales. } \\
\text { Preservar la vida. } \\
\text { Dialógica. }\end{array}$ \\
\hline Desarrollo & $\begin{array}{l}\text { Proceso de } \\
\text { enriquecimiento } \\
\text { material, por } \\
\text { el incremento } \\
\text { del volumen de } \\
\text { producción de } \\
\text { bienes y servicios. } \\
\text { Relaciones de } \\
\text { competencia. } \\
\text { Calidad de vida. }\end{array}$ & $\begin{array}{l}\text { En armonía y equilibrio } \\
\text { con los derechos de la } \\
\text { Naturaleza. } \\
\text { Relaciones de solidaridad, } \\
\text { reciprocidad, igualdad y } \\
\text { respeto por la Naturaleza. }\end{array}$ & $\begin{array}{l}\text { Economía comunitaria } \\
\text { complementaria. } \\
\text { Mejoramiento social. }\end{array}$ \\
\hline
\end{tabular}




\begin{tabular}{|c|c|c|c|}
\hline $\begin{array}{c}\text { Factor/ } \\
\text { Paradigma }\end{array}$ & Capitalismo & Buen vivir & $\begin{array}{c}\text { Fundamento } \\
\text { del buen vivir }\end{array}$ \\
\hline Producción & $\begin{array}{l}\text { Consumo, } \\
\text { material. }\end{array}$ & $\begin{array}{l}\text { Reproducción de la vida } \\
\text { feliz. }\end{array}$ & $\begin{array}{l}\text { Indivisibilidad de } \\
\text { la vida humana y la } \\
\text { naturaleza. }\end{array}$ \\
\hline Recursos & Objetos & Seres & Ayllu \\
\hline Progreso & $\begin{array}{l}\text { Individualismo, } \\
\text { consumismo. }\end{array}$ & Vivir bien. & $\begin{array}{l}\text { Todos van juntos, que } \\
\text { todos tengan todo. }\end{array}$ \\
\hline Agricultura & Monocultivo & Multicultivo & Términos de vida \\
\hline Trabajo & $\begin{array}{l}\text { Acto económico, } \\
\text { equivalente al } \\
\text { empleo. }\end{array}$ & $\begin{array}{l}\text { Acto social, espacio de } \\
\text { libertad y goce en relación } \\
\text { con los otros. }\end{array}$ & Criar la vida. \\
\hline Ser humano & $\begin{array}{l}\text { Virus, cáncer de } \\
\text { la Madre Tierra, } \\
\text { depredador. }\end{array}$ & $\begin{array}{l}\text { Una parte del todo. Los } \\
\text { seres humanos y los } \\
\text { elementos de la naturaleza } \\
\text { se relacionan con respeto } \\
\text { porque todo tiene vida. }\end{array}$ & $\begin{array}{l}\text { Plenitud y felicidad } \\
\text { colectiva e individual } \\
\text { de la humanidad. }\end{array}$ \\
\hline Sociedad & $\begin{array}{l}\text { Clasista. } \\
\text { Jerarquizada, } \\
\text { patriarcal, } \\
\text { dominante y } \\
\text { excluyente. } \\
\end{array}$ & $\begin{array}{l}\text { Comunidad plural. Sin } \\
\text { ningún tipo de dominación. }\end{array}$ & $\begin{array}{l}\text { Nueva civilización. } \\
\text { anclados en la } \\
\text { solidaridad, el } \\
\text { equilibrio y la } \\
\text { complementariedad. }\end{array}$ \\
\hline Comunidad & $\begin{array}{l}\text { Unidad y } \\
\text { estructura social. }\end{array}$ & $\begin{array}{l}\text { Sistema de organización } \\
\text { de vida, todo vive, todo } \\
\text { es importante para el } \\
\text { equilibrio. }\end{array}$ & $\begin{array}{l}\text { Unidad y estructura de } \\
\text { vida, ayllu, equilibrio y } \\
\text { armonía. }\end{array}$ \\
\hline Relacionamiento & Individualismo & Ayuda mutua, reciprocidad. & Ayni \\
\hline $\begin{array}{l}\text { Formas de } \\
\text { Relación }\end{array}$ & Dominación & $\begin{array}{l}\text { Complementaria para } \\
\text { el perfecto equilibrio. } \\
\text { Afectivo. }\end{array}$ & Conciencia del ayni \\
\hline Territorio & $\begin{array}{l}\text { Relaciones de } \\
\text { poder, condiciones } \\
\text { de apropiación. }\end{array}$ & $\begin{array}{l}\text { Espacio de disputa } \\
\text { civilizatoria. } \\
\text { Proceso social, cultural } \\
\text { histórico y de sabiduría. } \\
\text { Es emancipación del } \\
\text { proceso social en su } \\
\text { interacción con la } \\
\text { materialidad. }\end{array}$ & $\begin{array}{l}\text { Uso y convivencia de } \\
\text { los elementos desde } \\
\text { la concepción del } \\
\text { mundo. }\end{array}$ \\
\hline
\end{tabular}

Fuente: elaboración propia

Desde esta interpretación, los intelectuales neomarxistas latinoamericanos o intelectuales orgánicos asumieron su rol protagónico en la elaboración de una 
nueva forma de revolución y adoptaron los legados de los pueblos ancestrales cuya interpretación anticapitalista los aproxima a la promoción y aplicación de un discurso que, al alejarse del marxismo, no produce rechazo y contribuye a la mutación del sentido común. Complementado con la exaltación de las resistencias de los pueblos indígenas, este discurso promueve la resistencia de los demás movimientos sociales dentro del proceso civilizatorio.

Ante el desafío del colapso sistémico, los zapatistas de Chiapas abren el cambio de milenio cuestionando los ámbitos de la política y la democracia y evidenciando la diversidad de societalidades que conviven subordinadamente con la capitalista, y que más que representar la incompletud o polaridad del llamado progreso destacan la existencia de visiones de futuro subalternas y disidentes de la modernidad (...) contra la individualidad, la fragmentación y la pérdida de sentidos que reclama una territorialidad comunitaria no saqueadora. (Ceceña15)

En la intención civilizatoria de revolución o paradigma cultural de la vida, el proceso de liberación busca la construcción de nuevos consensos sobre el devenir de la humanidad a través de la promoción de nuevas construcciones cognitivas emancipadoras que, desde el pensamiento crítico, permitan la formulación de nuevas realidades y liderazgos que surjan de la articulación del marxismo con los demás saberes. Así:

Los procesos de formación permanente son espacios para fortalecer la concientización, a la vez que permiten el intercambio crítico, el diagnóstico de problemas comunes, la articulación de estrategias y la creación de nuevos liderazgos (...) El pensamiento social crítico se define a partir de la tarea teórica de recuperar el carácter creador del marxismo en diálogo con otros saberes y epistemologías críticas que enfrentan las lógicas enajenadoras capitalistas. (Galfisa 3)

En la praxis revolucionaria, la adopción del buen vivir para la revolución neomarxista latinoamericana se expresa en diversos procesos políticos. Por ejemplo, los de Evo Morales en Bolivia y Rafael Correa en Ecuador quienes, desde sus especificidades, le dan aplicación al socialismo del buen vivir. Sin embargo, llama la atención la práctica del proceso bolivariano de Hugo Chávez Frías quien lo incorpora en el seno del Partido Socialista Unido de Venezuela (PSUV) en las Líneas Estratégicas de Acción Política. 
Estas permiten construir el paradigma de la interpretación colectiva en la que el partido el PSUV, como plataforma del desarrollo y fortalecimiento del poder popular y la construcción del Gran Polo Patriótico, adelanta una audaz política de repolitización (Peña 1):

Optar por la lógica del partido-movimiento implica posicionarse dentro de las masas populares, estableciendo y desplegando una amplia política de alianzas con las diversas formas de organización popular, incluyendo los sectores patrióticos y democráticos de las clases medias, apoyándolas e invitándolas a poner su talento y conocimiento al servicio de la construcción de una sociedad del buen vivir para todos y todas (...) Las Bases de Patrulla y Círculos de Luchas Populares y del Buen Vivir tendrán la responsabilidad de elaborar el mapa de los conflictos y problemas sociales generados por el capitalismo (PSUV 4).

En esa medida, la expresión buen vivir o vivir bien proveniente de los pueblos originarios ha sido hábilmente valorada y promovida para tomar la cosmovisión y los saberes de sus entrañas. Así, se elabora, a partir de ellos, un gran discurso que le permita al neomarxismo impulsar la confrontación del paradigma capitalista de manera sutil e imperceptible, con el fin de que, bajo el modelo de revolución cultural, produzca el cambio civilizatorio: "el Buen Vivir, en realidad, se presenta como una oportunidad para construir y reconstruir colectivamente nuevas formas de vida" (Acosta 301).

Finalmente, resulta importante destacar que la elaboración teórica de la revolución cultural puede ser tan auténtica que el mismo término puede ser considerado de su propia elaboración:

El origen del concepto es incierto, a tal punto que la antropóloga británica A. Spedding afirma que "el suma qamaña no existe en la realidad etnográfica ni popular; no existe fuera de la cabeza de algunos intelectuales ilusos; (...) es una especia de fantasía de puros valores de uso, donde el valor de cambio está ausente". (Gómez 206)

De acuerdo con sus afirmaciones y otras voces críticas, Andrés Uzeda plantea que se trataría de una manifestación o discurso culturalista de las élites intelectuales aymaras, formadas en una tradición académica antropológica, etnológica o etnohistórica (Cardoso 2). 


\section{Conclusiones}

Con el colapso del socialismo real o marxismo leninismo, desde América Latina se impulsó un proceso de reflexión y autocrítica que permitiera rescatar al marxismo de las tesis del fin de la historia de Fukuyama. Desde este ejercicio, y tras caracterizar al capitalismo neoliberal como tesis inhumana, se renueva la vertiente humanista del marxismo que adopta la filosofía de la praxis y la revolución cultural para occidente de Antonio Gramsci e impulsa un proceso civilizatorio que conduzca a la humanidad a su emancipación.

Desde este contexto, se registra la emergencia de nuevas tesis alternativas inspiradas en los pueblos ancestrales que le permiten al marxismo reeditarse para atraer la multiplicidad de movimientos antisistémicos. De esta manera, la confrontación o choque de paradigmas se produce entre el capitalismo neoliberal con su modelo desarrollista y el marxismo humanista que, desde los postulados del buen vivir o vivir bien, se presenta como tesis renovada que enmascara el neomarxismo.

En este sentido, el proceso civilizatorio se desenvuelve bajo el esquema de revolución cultural. Por consiguiente, el campo de batalla está al interior de la sociedad civil, escenario de confrontación de ideas en la que los sectores protagónicos polarizados se disputan las realidades y los valores. En la disputa por la hegemonía, las trincheras o casamatas están simbolizadas por la familia, la educación, la religión, los partidos políticos, los movimientos sociales y los medios de comunicación. Según Gramsci, estas son instituciones formadoras del sentido común y constituyen la superestructura; en esa medida, son los objetivos sobre los que debe trabajarse para eliminar los saberes impuestos por el capitalismo y construir los valores liberadores del Sumak kawsay o Sumak qamaña:

Gramsci corrige (...) la férrea trabazón que el marxismo (sobre todo el marxismo escolástico) establece entre la infraestructura o estructura (las fuerzas y relaciones de producción: de producción de las condiciones materiales de la existencia) y la superestructura: religión, Estado, derecho, familia, etc. En esa corrección, Gramsci es drástico. La revolución, para él, debe pasar por la conquista de lo que pertenece al ámbito de la superestructura (la sociedad civil). La conquista de la sociedad política (poder del Estado) vendrá por sí sola. (Del Nose 17) 
En esta dinámica contrahegemónica, desde los pueblos zapatistas, aymara, quechua y mapuche se erigen cosmovisiones renovadoras que se adaptan a la modernidad para confrontar a nivel global los problemas del consumismo, el corporativismo, el mercantilismo y la acumulación como causas de la crisis política, económica y social que inspiran la formulación de alternativas emancipadoras.

En el Foro de Sao Pablo, la organización que agrupa a las izquierdas latinoamericanas en la batalla contra el capitalismo neoliberal, se esboza la adopción del buen vivir para el socialismo como instrumento que permita la articulación de las demás expresiones anti-sistémicas.

La adopción y promoción del buen vivir o vivir bien por parte de los movimientos sociales y populares latinoamericanos alienta la movilización y la confrontación contra los gobiernos de la región que, identificados con el modelo capitalista neoliberal, persisten en su modelo de vida. En este sentido, desde sus cosmovisiones, los movimientos antisistémicos enfrentarán las tesis que defienden los gobernantes neoliberales mediante los mecanismos de democracia directa y expresiones de poder popular buscando legitimar sus postulados.

Epistemológicamente, los fundamentos expuestos por el buen vivir y manipulados por el neomarxismo describen una cosmovisión diametralmente opuesta a la fundamentada por el modelo de capitalismo neoliberal. Por esta razón, se reconoce la existencia de un choque difícilmente conciliable entre estos dos paradigmas. Uno y otro, desde sus tesis, reeditan la lucha por el fin de la historia.

Los gobiernos de la región encontrarán una fuerte oposición por parte de los movimientos antisistémicos, sociales y populares ante el diseño de políticas públicas en materia energética, agrícola, minera, económica, de ordenamiento territorial y social, así como la planeación e implementación de proyectos productivos nacionales o extranjeros de minería extractivista, de cultivos extensivos y de energía alternativa. Estos movimientos, bajo el concepto del buen vivir, darán la batalla contra toda decisión que vaya en contravía de la armonía, el respeto y el equilibrio que debe existir entre el ser humano y la naturaleza. 
Finalmente, con el advenimiento del marxismo humanista o crítico como vertiente hegemónica del marxismo latinoamericano, y bajo los preceptos del buen vivir o vivir bien como alternativa al modelo de desarrollo promulgado por el capitalismo, se reedita para el nuevo siglo un espacio de confrontación de paradigmas. Desde la revolución cultural y con la desalienación y alienación de la avalancha de saberes, de valores y verdades, se buscará la mutación del sentido común como factor determinante en la conquista de la hegemonía:

Una verdadera encrucijada civilizatoria que llama a una subversión del pensamiento, de las prácticas sociales, de la sujetidad, de las instituciones, de las percepciones y de los saberes. Desajenación, desfetichización y descolonización. Dislocación epistemológica y refundación social. Ese aparece como el reto del nuevo milenio (Ceceña14).

\section{Referencias}

Acosta, Alberto. "El buen vivir como alternativa al desarrollo. Reflexiones desde la periferia de la periferia". Reinventar la izquierda en el siglo XXI hacia un diálogo Norte - Sur. Eds. José Luis Coraggio y Jean-Louis Laville. Los Polvorines: Universidad Nacional de General Sarmiento, 2014. 299 - 312.

Bertinant, Pablo y Chemes, Jorge. "Aportes del sector energético a una transición socioecológica". Documento de discusión IV Cumbre Cooperativa de las Américas, 2011. Disponible en: https://www.aciamericas.coop/IMG/pdf/1.2_ pablo_bertinat_-_jorge_chemes.pdf

Boff, Leonardo. "El buen vivir". Rebelión. 11 abr. 2009. Consultado: febrero, 2019. Disponible en: http://www.rebelion.org/noticia.php?id=83624

Biagini, Hugo y Roig, Arturo. Diccionario del pensamiento alternativo. Buenos Aires: Biblos, 2008.

Cabrales, Omar. "El Principio del buen vivir o Sumak Kawsay como fundamento para el decrecimiento económico". Cuadernos de filosofía latinoamericana 36. 113 (2015): 83- 99.

Calle, Eneko y González Javier. "Ana Esther Ceceña: la herramienta más eficaz y peligrosa para la dominación no son los misiles, sino hacernos desear ser poderosos". Pueblos Revista de información y debate. (2016): 11-21.

CAOI. Buen Vivir / Vivir bien, filosofía, políticas estrategias y experiencias regionales andinas. Lima: Coordinadora Andina de Organizaciones Indígenas, 2010.

Cardoso-Ruiz, René. "Elementos para el debate e interpretación del Buen vivir/Sumak Kawsay". Contribuciones desde Coatepec. 31 (2016): 49-66. 
Ceceña, Ana. "Por la humanidad y contra el Neoliberalismo. Líneas centrales del discurso zapatista”. Resistencias mundiales (De Seattle a Porto Alegre). Comp. José Seoane y Emilio Taddei. Buenos Aires: CLACSO, 2001. 131-140.

Ceceña, Ana. "El zapatismo: De la inclusión en la nación al mundo en el que quepan todos los mundos". América Latina y el desorden global universal. Comp. José María Gómez. Buenos Aires: CLACSO, 2004. 301-320

Ceceña, Ana. Del desarrollo al "Vivir Bien": la subversión epistémica. México: Colección de Libros Problemas del Desarrollo, 2014.

Conde, Santiago. "El antisistema será aquel que se oponga de manera frontal a una Totalidad Sistemática Circular dada, sea esta el Estado o el Sistema de Modos de Producción". El Catoblepas 68. (2007): en línea.

Coraggio, José. "Presentación de textos latinoamericanos". Reinventar la izquierda en el siglo XXI hacia un diálogo Norte - Sur. Comp. José Luis Coraggio y Jean-Louis Laville. Los Polvorines: Universidad Nacional de General Sarmiento, 2014.

Cortés, Darío y Cerón, Alejandra. "El neomarxismo y la cultura política de la emancipación". Mutación de las revoluciones: Del marxismo leninismo al marxismo humanista. Ed. César Augusto Niño González. Bogotá: Escuela Superior de Guerra, 2017. 49-76.

Cortés, Darío. "El EZLN, fuente de inspiración en la lucha contra el capitalismo neoliberal". Estudios en seguridad y defensa. Bogotá: Escuela Superior de Guerra, 2015.

Cruz, Edwin. "Hacia una ética del vivir bien - buen vivir". Producción + limpia, 2014. Vol. 9 No 2. 11-22. Disponible en: http://www.scielo.org.co/pdf/pml/v9n2/ v9n2a02.pdf

Del Noce, Augusto. Italia y el Eurocomunismo, una estrategia para occidente. Madrid: Magisterio Español, 1977.

De Sousa, Boaventura. “¿Reinventar las izquierdas?” Reinventar la izquierda en el siglo XXI hacia un diálogo Norte - Sur. Ed. José Luis Coraggio y Jean-Louis Laville. Los Polvorines: Universidad Nacional de General Sarmiento, 2014. 143-164.

Escobar, Arturo. "De la crítica al desarrollismo al pensamiento sobre otra economía: pluriverso y pensamiento relacional”. Reinventar la izquierda en el siglo XXI hacia un diálogo Norte - Sur. Ed. José Luis Coraggio y Jean-Louis Laville. Los Polvorines: Universidad Nacional de General Sarmiento, 2014.191- 206.

Exeni, José. “Bolivia: Las autonomías indígenas frente al Estado plurinacional”. ¿Cómo transformar? Instituciones y cambio social en América Latina y Europa. Quito: Fundación Rosa Luxemburgo/Abya-Yala, 2015.

Galfisa. "Los procesos de articulación política emancipadora. El desafío de la construcción teórica: Los movimientos sociales en los nuevos escenarios”. América Latina en movimiento. Grupo América Latina: Filosofía social y Axiología. 449 (2009).

Girbal, Noemí. "Memoria, olvido e identidad. Caminos transitados y atajos traumáticos en la historia argentina". América Latina hacia su segunda independencia. Memoria y autoafirmación. Buenos Aires: Alfaguara, 2007. 
Gómez, Amparo. T.S Khun y las ciencias sociales. Madrid: UNED, 1997.

Gómez, Alfredo. "El Vivir bien una crítica cultural del capitalismo". Ciencia política 13. 25 (2018): 199-222.

Grupo de Trabajo Foro de Sao Pablo. Consenso de nuestra América, proyecciones para un programa político de acuerdos de la izquierda, los partidos y movimientos populares de América Latina y el Caribe. Managua: Foro de Sao Pablo, 2017.

Gudynas, Eduardo. "Post extractivismo y alternativas al desarrollo desde la sociedad civil. Alternativas al capitalismo del siglo XXI”. Quito: Fundación Rosa Luxemburgo/Abya-Yala, 2015.

Hidalgo, Francisco. Contrahegemonía y buen vivir en la fase posneoliberal. Gramscimanía- 2013. Consultado: febrero 2019. Disponible en: http://www. gramscimania.info.ve/2013/06/contrahegemonia-y-buen-vivir-en-la-fase.html

Katz, Claudio. Neoliberalismo, neodesarrollismo, socialismo. Buenos Aires: Batalla de ideas, 2015.

Lang, Miriam y Brand, Uirich. ¿Cómo transformar? Instituciones y cambio social en América Latina y Europa. Quito: Fundación Rosa Luxemburgo/Abya-Yala, 2015.

Lao, Agustín. Crisis de la civilización occidental capitalista y movimientos antisistémicos. Massachusetts: Universidad de Massachusetts, 2011.

Lukács, Georg. Historia y conciencia de clase. La Habana: Editorial de ciencias sociales del Instituto del Libro, 1970.

Martínez, Fernando. Pensamiento latinoamericano, cultura e identidades. El desafío de la construcción de la teoría: Los movimientos sociales en los nuevos escenarios. América Latina en movimiento. Publicación internacional de la agencia latinoamericana de información. 449 (2009): 4-7.

Marx, Karl. Manuscritos economía y filosofía. Madrid: Alianza, 1974.

Medina, Javier. “Acerca del Suma Qamaña”. Vivir Bien paradigma: Paradigma no capitalista. La Paz: Plural editores, 2011.

Miranda, Esther. "El movimiento Zapatista: La lucha contra el neoliberalismo mundial”. EOM El orden mundial. 2016. Consultado: Enero 2019. Disponible en: https://elordenmundial.com/el-movimiento-zapatista/

Munck, Ronaldo. "La teoría crítica del desarrollo: resultados y prospectiva”. Migración y desarrollo 18. 14 (2010): 35-57.

Palacín, Miguel. "Prólogo”. Buen Vivir / Vivir bien, filosofía, políticas estrategias y experiencias regionales andinas. Ed. Miguel Palacín Quispe. Lima: Coordinadora andina de organizaciones indígenas, 2010. 7.

Peña, Geovanni. "Círculos de lucha popular. Ideología y socialismo del Siglo XXI". Aporrea. 20 nov 2014. Disponible en: https://www.aporrea.org/ideologia/a198670. html.

PSUV. Líneas estratégicas de acción política. Caracas: Partido Socialista Unido de Venezuela, 2011.

Sada, Daniel. "Crítica al capitalismo". Gilbert Keith Chederson y el distributismo inglés en el primer tercio del siglo XX. José Luis Pérez y López de Ayala. Colección tesis doctorales Cum Laude. Madrid: Fundación Universitaria Española, 2003. 65-87. 
Sánchez, Adolfo. Filosofía de la praxis. México: Grijalbo, 1980.

Sotelo, Adrián. América Latina: De crisis y paradigmas. La teoría de la dependencia en el siglo XXI. México: Plaza y Valdés, 2005.

Streck, Danilo, Redin, Euclides y Zitkoski, Jaime. Diccionario Pablo Freire. Lima: Consejo de Educación Popular de América Latina y el Caribe, 2015.

Uzeda, Andrés. "Elementos para el debate e interpretación del Buen vivir/Sumak Kawsay". Contribuciones desde Coatepec. México: Universidad Autónoma del Estado de México, 2016.

Valdés, Gilberto. "Movimientos antisistémicos y gobiernos populares: nuevos desafíos". El desafío de la construcción teórica: Los movimientos sociales en los nuevos escenarios. Quito: América Latina en movimiento, 2009. 